\title{
The Journal of Economics and Politics
}

Volume 25

Issue 2 Special Issue

Article 3

2020

\section{Assessing the Economic Impact of Sovereignty Transfer Over Hong Kong: A Synthetic Control Approach}

Jing Li

Miami University, lij14@miamioh.edu

Sarina Sangal

Miami University, sangals2@miamioh.edu

Ling Shao

Miami University, shaol2@miamioh.edu

Follow this and additional works at: https://collected.jcu.edu/jep

\section{Recommended Citation}

Li, Jing; Sangal, Sarina; and Shao, Ling (2020) "Assessing the Economic Impact of Sovereignty Transfer Over Hong Kong: A Synthetic Control Approach," The Journal of Economics and Politics: Vol. 25 : Iss. 2, Article 3.

Available at: https://collected.jcu.edu/jep/vol25/iss2/3

This Abstract is brought to you for free and open access by Carroll Collected. It has been accepted for inclusion in The Journal of Economics and Politics by an authorized editor of Carroll Collected. 
Assessing the Economic Impact of Sovereignty Transfer Over Hong Kong:

A Synthetic Control Approach

Jing Li, Miami University (lij14@miamioh.edu)

Sarina Sangal, Miami University (sangals2@miamioh.edu)

Ling Shao, Miami University, (shaol2@miamioh.edu)

\begin{abstract}
This paper aims to quantify the effect of sovereignty transfer on Hong Kong's economy. It compares the trajectory of Hong Kong's purchasing power parity (PPP) adjusted GDP per capita before and after the 1997 handover with the trajectory of a weighted combination of similar economies, including Japan, Singapore, South Korea and Taiwan. Using weights endogenously determined by data, we construct a synthetic Hong Kong to provide the counterfactual of what would have happened to Hong Kong's economy in the absence of transfer of sovereignty. By combining multiple economies as control, the synthetic approach is more robust than simply comparing Hong Kong to another similar economy before and after the 1997 handover. It also provides an interval estimate of possible treatment effects. We find that Hong Kong's economy is negatively affected by the handover. The gap between actual and synthetic Hong Kong in PPP adjusted GDP per capita from 1997 to 2001 is on average 7\% of the 1996 level if Japan receives the greatest weight. The average negative effect becomes $9 \%$ if Singapore receives the greatest weight. The paper concludes by discussing possible confounding factors in the results, such as isolating the impact of the 1997 Asian Financial Crisis from the sovereignty transfer on Hong Kong's economy.
\end{abstract}

Link to complete paper:

https://www.fsb.miamioh.edu/lij14/index.html 